\title{
DEVELOPER'S VIEWS ON INFORMATION SYSTEMS QUALITY AND SUCCESS IN CANADIAN SOFTWARE DEVELOPMENT FIRMS
}

\author{
Delroy Anthony Chevers \\ The University of the West Indies, Jamaica \\ Gerald Grant \\ Carleton University, Canada
}

\begin{abstract}
For years software developers have struggled in their attempts to deliver high quality and successful software products. A survey was conducted in Canada to assess the main determinants of information systems (IS) quality and success. The survey confirmed the notion that developer skills and contribution had the greatest impact on information systems quality, over process maturity and the application of the latest technology. The survey also discovered that user perception had a greater impact on IS success in comparison to IS quality. In an attempt to gain deeper insights into the state of IS quality and success in Canada, interviews were conducted with Canadian software developers. The interviews revealed that organization climate such as top management support, the social interactions and dynamics among project team members and the structural analysis of the industry are other factors which can influence the quality and success of the delivered software product. These insights if applied during the development and delivery of information systems can enhance the likelihood of producing high quality and successful software products and increase the competitiveness of these firms.
\end{abstract}

Keywords: Canada, information systems quality, information systems success, organization climate, process maturity

\section{INTRODUCTION}

Millions of dollars are being invested by firms in information systems in an effort to gain a competitive advantage (Kamel, Rateb and El-Tawil, 2009; Qureshi, 2009). However, the expected benefits of these investments are not being realized because for years software developers have struggled in their attempts to deliver high quality software products with the requisite features and functionalities (Bulatovic, 2011; Laporte and O'Connor, 2016; Luftman

Manuscript first received/Recebido em: 2017/03/17 Manuscript accepted/Aprovado em: 2017/04/17

Address for correspondence / Endereço para correspondência

Delroy Anthony Chevers, The University of the West Indies, Jamaica. E-mail: delroy.chevers@uwimona.edu.jm

Gerald Grant, Carleton University, Canada. E-mail: gerald_grant@ carleton.ca

Published by/ Publicado por: TECSI FEA USP - 2016 All rights reserved 
and Ben-Zvi, 2010). The aggregate failure rate of these information systems projects (challenged and failed) is $71 \%$ (Hastie and Wojewoda 2015).

It is widely accepted in the IS community that there are three main factors that influence the quality of software products. These are people, technology and process maturity (EspinosaCuriel, Rodriguez-Jacobo, and Fernandez-Zepeda, 2013; Gorla and Lin, 2010; Niazi, 2012). The people involved (developers and users) in the development and use of the software, the technology used in the developmental process, and the maturity of the software development process can impact the quality of the delivered product. Maturity in this study is defined as the degree to which the process is defined, managed, measured and continually improved (Dooley, Subra and Anderson, 2001).

It is believed that careful analysis of the delivery process is the most influential of the three factors (process, people and technology) to IS quality (Humphrey 1989, SEI 2010). This view has led to the birth and popularity of software process improvement (SPI) programs. As a result, many software development firms have adopted SPI programs in an attempt to overcome the problem of the delivery of low quality software products and seek to produce higher quality products. Scholars have posited the benefits of SPI programs, which include reduced project cycle time, reduced developmental cost, improved staff productivity, improved customer satisfaction, and improved software quality (Krishnan and Keller, 1999; Niazi and Babar, 2009; Sulayman, Urquhart, Mendes and Seidel, 2012; Dalton, 2016; Laporte and O'Connor, 2016). It is argued that the development and delivery of high quality software products can enhance the success rate of information systems projects, as well as increase the competitiveness of these firms (Kamel et al., 2009; Qureshi, 2009).

However, despite the stated benefits, the uptake of SPI programs is low (Staples, Niazi et al. 2007, Laporte and O'Connor 2016) because the implementation of these programs is believed to be costly, time consuming, disruptive and bureaucratic (Niazi, Babar and Verner, 2010; Laporte and O'Connor, 2016). However, quite recently Canada has experienced significant growth in information and communication technology (ICT) opportunities (Mignone and Henley 2009). This growth is expected to have a positive impact on socioeconomic development in the country (Mignone and Henley 2009).

The objective of this study was to ascertain the views of Canadian software developers about the state of information systems quality and success in Canada. A mixed method approach was taken in this study. Firstly, a survey was conducted to assess the determinants of IS quality and IS success. Figure 1 outlines the research model of the survey, in which five hypotheses are highlighted. Secondly, upon completion of the survey and its findings, the researchers conducted interviews with Canadian software developers to ascertain deeper insights regarding the survey results. Effectively, the interviews sought answers to the following research questions:

1. What are the views of Canadian software developers regarding the factors with the greatest impact on IS quality?

2. What are the views of Canadian software developers regarding the factors with the greatest impact on IS success? 


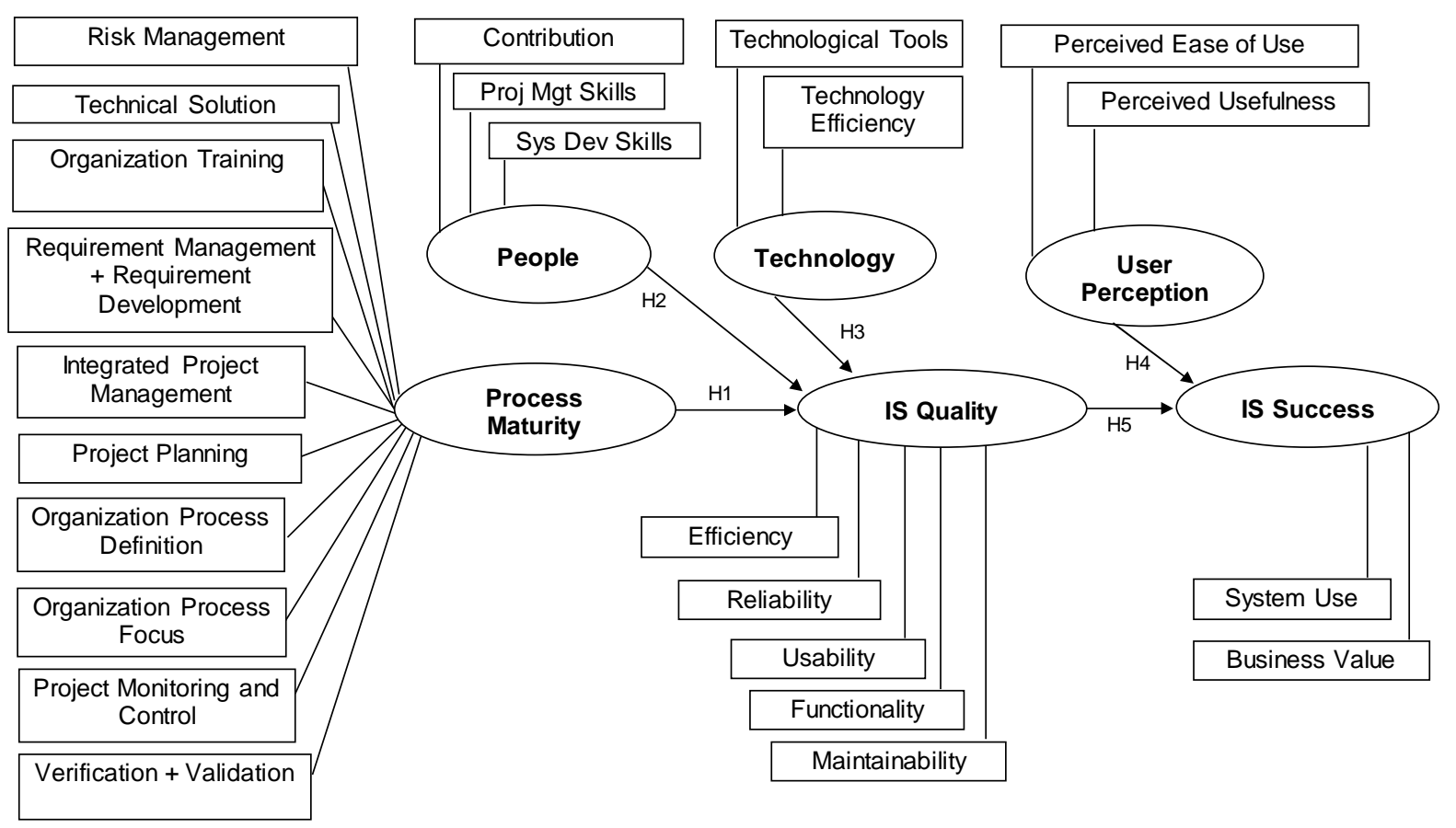

Figure 1. The Research Model.

The insights gained from this study can enhance the likelihood of producing high quality and successful software products and increase the competitiveness of Canadian software development firms.

\section{LITERATURE REVIEW}

Firms have been investing millions of dollars in information systems in an effort to support business functions and gain a competitive advantage (Jeong and Yoon 2016). However, the expected benefits of implementing information systems such as increased competitive advantage have been elusive largely because the information systems lack the requisite features and functionalities (Duggan 2006). The failure rate of information systems projects currently stands at $71 \%$ (Hastie and Wojewoda 2015). A failed project is one that is cancelled prior to completion or delivered and never used (Standish Group, 2013).

In an effort to increase the delivery of high quality and more successful software products many firms have adopted SPI programs. There is the notion that the faithful application of SPI programs can reduce the reliance on individual and project team members' heroics for quality outcomes (Duggan 2006). These programs establish process repeatability and predictability which can manifest themselves in the delivery of high-quality software products. This increases the competitiveness of these firms, which by extension increases the probability of winning contracts in the global market (Niazi, Babar et al. 2010, Sulayman, Urquhart et al. 2012). 
Firms want to grow and develop, especially in a competitive industry like the software development market. Such growth and development can be achieved with the acquisition of resources (DiMaggio and Powell, 1983). SPI is viewed as a resource which can provide a competitive advantage (Iversen and Ngwenyama, 2006; Sulayman et al., 2012). The tenet of the institutional theory of organizational growth refers to developing value-creation skills and the desire by firms to be similar. The theory studies how organizations can increase their ability and survive in a competitive environment by satisfying their stakeholders (DiMaggio and Powell 1983). Firms seek to become more alike and fit-in the industry by following the leader and conforming to the rules and the prevailing practices in the industry (DiMaggio and Powell 1983). The theory explores the processes by which structures, rules, norms and practices become established in the industry.

SPI programs are a set of established practices that if followed can advance firms along with a process maturity continuum (Paulk et al., 1995). There are five maturity levels with level 1 described as chaotic because there are no established practices, but at level 2 there are a number of established project management practices like requirements management and project planning. Level 3 seeks to introduce some organizational practices like organizational training and risk management. Level 4 institutes key performance indicators like organizational process performance to assess how well the firm is doing in the area of process improvement. At level 5 the practices are documented, understood, followed, measured and institutionalized and so a culture of continuous improvement is created. This culture lends itself to practices such as organizational innovation and deployment in which new and better ways are created in software development. Firms must be assessed at level 3 and above to win global contracts (Niazi, Babar et al. 2010), especially US Defence projects.

It is for this reason that firms seek to mimic the best practices of industry leaders, or recruit employees from their competitor who possess the requisite programming, business analysis and/or project management skills. Software developer retention has been a problem in many organizations for years (Westlund and Hannon 2008). When knowledgeable developers resign, they leave with critical knowledge of business processes, policies, procedures and practices that are essential in maintaining a competitive advantage (Westlund and Hannon 2008). In response, some firms gain the tacit knowledge of newly recruited employees, while others lose critical and valuable know-how. Such employee turnover can create a scarcity of good and qualified software developers in some firms. Coupled with this scarcity is the notion that $67 \%$ of firms who attempt to adopt SPI programs usually abandon the effort before realizing its potential benefits (Krasner 2001). This is so because the implementation of SPI programs require considerable investments in people, time and financial resources (Ngwenyama and Norbjerg 2010, Pino, Pardo et al. 2010). The strategies of adopting the best practices of industry leaders and recruiting knowledgeable employees from competitors are described as mimetic and normative isomorphism in the institutional theory. Such strategies can allow firms to not only survive in a very competitive industry but also to strive.

\section{METHODOLOGY}


A pre-test of the survey instrument was conducted with seventeen IS researchers, research methodologists and graduate IS students in Jamaica and Trinidad. Feedback was provided in terms of time to complete the survey and the identification of ambiguous or compounded questions. Adjustments were made to the survey instrument based on the feedback. The survey items were anchored on a 7-point Likert-type scale, with (1) being strongly disagree and (7) being strongly agree.

For the real survey, email invitations were sent to 344 potential respondents. Respondents were selected from a sample frame that was developed by the researchers through the Canadian Company Capabilities Database, as well as personal referrals. The unit of analysis was software development project. A total of sixty-one (61) responses were collected, but six were incomplete and had to be discarded. As a result, only 55 responses were analyzed. This gave a $16 \%$ response rate.

The profile of the fifty-five respondents in the survey included 44 males and 11 females. They were chief information officers (CIOs), analysts, programmers, developers, administrators and project managers. $22 \%$ of the respondents were CIOs and the average years of service in the software industry were 15.2 years. The profile of respondents could be considered somewhat skewed towards the more senior personnel in terms of hierarchy and years of service in the software industry.

On the other hand, telephone interviews, face-to-face site visits and email communication were used to collect the data for the interview sessions. The focus of these interviews was software developers/project managers' views regarding the rationale for the survey findings. A total of 64 invitations were sent, but only 25 interviews were conducted. This gave a 30\% response rate. Participants included 23 male and 2 female Canadian software developers working in the cities of Toronto, Ottawa and Montreal. These cities were selected based on proximity and convenience to the researcher. The majority of the participants were software developers and the majority of them were holders of bachelor degrees. The results of the survey and the interviews are set out below.

\section{FINDINGS AND DISCUSSION}

The Survey:

Partial least squares (PLS), a popular SEM technique was used as the statistical tool to evaluate both the measurement and structural models, and the bootstrap re-sampling method (500 re-samples) was used to determine the path significance of the structural model. PLS-Graph was selected for this study based on its ability to handle small sample sizes (Chin 2010). In 
addition, PLS has embedded measures that report on the reliability and validity of the survey items. In its output reports, PLS provides measures such as factor loadings, average variance extracted and composite reliability.

In evaluating the measurement model both reliability and validity were established. The composite reliability readings ranged from $0.824-0.981$, which is above the acceptable threshold of 0.70 (Chin 2010). In addition, the average variance extracted (AVE) score ranged from $0.610-0.944$, which is above the acceptable threshold of 0.50 (Fornell and Larcker 1981).

The results of the analysis of the structural model are shown in Table 1 and Figure 2. Table 1 outlines the loadings of the second order variables, which are all above the 0.70 threshold. Figure 2 shows the results of the five hypotheses. All hypotheses were significant with people, process maturity and technology explaining $76 \%$ of the variance in IS quality and perception and IS quality explaining $78 \%$ of the variance in IS success.

The participants in the interviews were shown the results of the survey and asked to comment on the findings. Appendix A provides further details regarding the interview questions and other information that was provided to facilitate the discussion such as definitions.

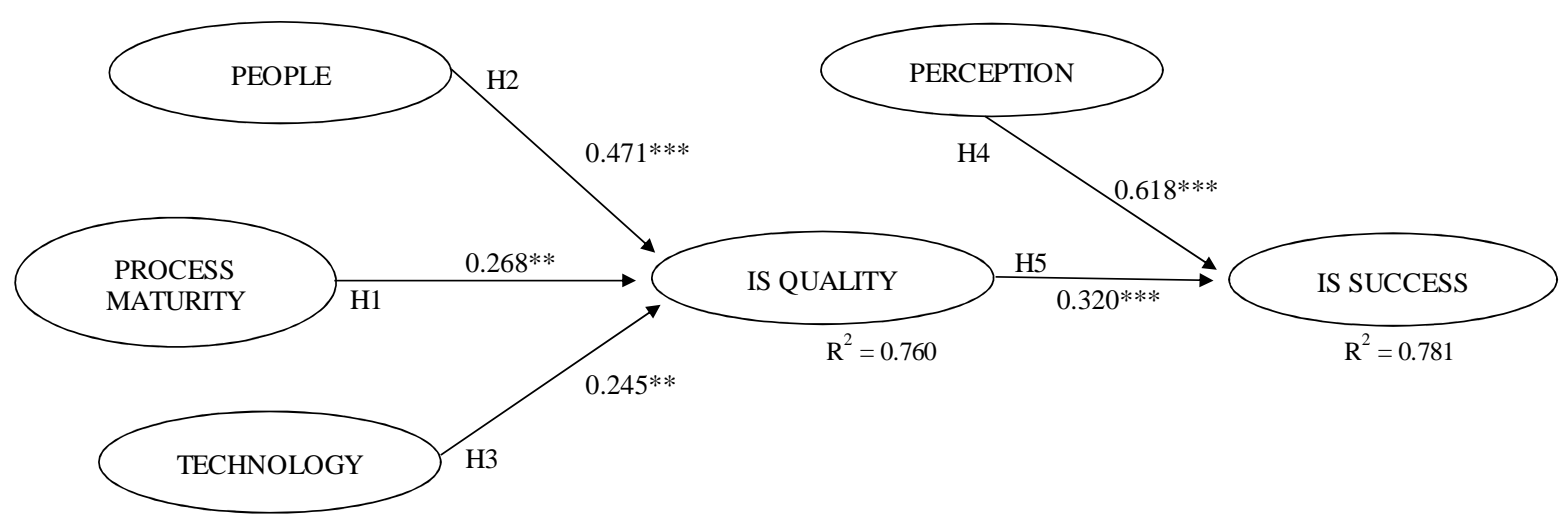

Figure 2. The Hypothesized Model.

Note: $* * * \mathrm{p} \leq 0.001 \quad * * \mathrm{p} \leq 0.05$ 
Table 1. Loadings of $2^{\text {nd }}$ Order Variables.

\begin{tabular}{|c|c|c|c|}
\hline Construct & Indicator Variable & Description & Loadings \\
\hline \multirow{10}{*}{ Process Maturity } & RSK (4) & Risk Management & 0.8526 \\
\hline & TS (3) & Technical Solution & 0.9411 \\
\hline & OT (3) & Organization Training & 0.7346 \\
\hline & RM (4) & $\begin{array}{l}\text { Requirements Management + } \\
\text { Requirements Development }\end{array}$ & 0.8745 \\
\hline & IPM (3) & Integrated Project Management & 0.8289 \\
\hline & $\mathrm{PP}(5)$ & Project Planning & 0.9151 \\
\hline & OPD (3) & Organization Process Definition & 0.7300 \\
\hline & OPF (3) & Organization Process Focus & 0.6585 \\
\hline & PMC (4) & Project Monitoring and Control & 0.9059 \\
\hline & VV (4) & Verification + Validation & 0.8685 \\
\hline \multirow{3}{*}{ People } & CON (3) & Contribution & 0.9104 \\
\hline & PMS (4) & Project Management Skills & 0.8991 \\
\hline & SDS (3) & Systems Development Skills & 0.9327 \\
\hline \multirow{2}{*}{ Technology } & TT (2) & Technology Tools & 0.9732 \\
\hline & $\mathrm{TE}(2)$ & Technology Efficiency & 0.9771 \\
\hline \multirow{5}{*}{$\begin{array}{l}\text { Information } \\
\text { Systems Quality }\end{array}$} & MA (3) & Maintainability & 0.8393 \\
\hline & REL (3) & Reliability & 0.8655 \\
\hline & EFF (2) & Efficiency & 0.8351 \\
\hline & FUN (3) & Functionality & 0.8566 \\
\hline & USA (3) & Usability & 0.8021 \\
\hline \multirow{2}{*}{ Perception } & PU (3) & Perceived Usefulness & 0.9466 \\
\hline & PEU (3) & Perceived Ease of Use & 0.9313 \\
\hline \multirow{2}{*}{$\begin{array}{l}\text { Information } \\
\text { Systems Success }\end{array}$} & SysUse (3) & System Use & 0.9120 \\
\hline & BusVal (3) & Business Value & 0.9379 \\
\hline
\end{tabular}

The Interview: 
The responses to question \#1 which seeks to explain why people skills and contribution had the greatest impact on information systems quality over technology and process maturity in Canada are as follows:

The majority of the respondents believed that human resource skills, effective communication and decision making abilities along the project life cycle are the main factors that contribute to the delivery of high quality software products. It was stated that people bring their skills set, knowledge and experience in the developmental process. There is the notion that the ability and freedom to clearly articulate what is required and what should be delivered is critical in developing high quality software. One respondent stated, "what is important is developer skill in software development to implement correctly and perform the verification and validation function." Furthermore, it is believed that knowledge sharing among project team members is more important than the adoption of the latest technology and the maturity of the developmental process. The result of a recent study showed that social factors like cultural barriers, user rejection and resistance to change are more influential than technical and cost factors in the successful implementation of IS projects (Merlo, Carneiro et al. 2016).

It was said that if developers have good people skills, then they can understand and develop effective solutions, and this would be reflected in the quality of the software they produce. In other words, the success of these projects depends on the efficiency and effectiveness of people (developers, programmers and project managers) skills and contribution. It was stated by one respondent that in Canada, project team members are willing to contribute and take responsibility for the development and delivery of high quality software products. It was pointed out those persons who can interpret both the ways the technology can be used and understand the needs of the client, will be able to produce better results at the end of the project. It is believed that good people tend to find their own undocumented tools and processes to maximize productivity during system development in a very competitive industry.

In terms of question \#2 which seeks to address the finding that technology had the lowest impact on information systems quality in Canada.

A large majority of the respondents believed that technology is a secondary tool which could be useless in improving quality without intelligent human interpretation and application. There is the expressed feeling that most software development firms in Canada, a developed country, can afford the latest technology. Hence, there should be no wide variation in the adoption of the latest technology by these firms in Canada. Furthermore, it is felt that individuals can easily learn how to navigate and utilize the latest technology because such knowledge is explicit. As a result, the acquisition and utilization of the latest technology does not necessarily lead to competitive advantage. On the other hand, people knowledge in some cases can be tacit and as such can create an advantage as some firms might find it difficult to capture or imitate this knowledge.

In responding to question \#3 about why the variance explained by people, process maturity and technology on information systems quality $\left[R^{2}\right]$ was 0.760 or $76 \%$, the responses are: 
The R-square could be considered high, but this is in alignment with the literature which states that people, process maturity and technology are the main determinants of information systems quality. However, the respondents suggested a number of other factors which could be summarized as follows:

- Size of firm

- Size of project

- User-community size

- Top management support

- Strength of the social interaction among project members

- Project team dynamics

- Organization climate and culture

- The structural analysis and dynamics of the industry - existence of a dominant leader or players of similar size, type of firm (in-house development, for sale), level of competition, time to market, bargaining power of clients/users, demand for new products, demand for quality products by clients/users, social trends, regulatory changes, etc.

Some of the above factors could be classified as control variables, some as mediating variables, while others may be seen as moderating variables in the research design.

Amidst these factors, the majority of respondents believed that the urgency to complete projects could affect the quality of the delivered software. The desire to meet stringent deadlines could result in little or no testing being conducted, which can result in the development and delivery of poor quality software products. In addition, the sales cycle of emerging software for firms who develop software for sale, as well as cost cutting measures could also impact quality. However, it is felt that these factors could be minimal because in general firms seek to become similar by adopting the best practices in the industry or those of very successful firms in the industry.

Question \#4 explored why perception had a greater impact on information systems success than information systems quality in Canada.

There are instances where high quality software are not utilized by users because of the perception of users regarding its usefulness, ease of use or its potential to reduce or replace their role and significance in the firm. The majority of the respondents felt that no matter how high developers rate the quality of the delivered software, quality is relative to the users' requirements, desires and preferences. This view was further expressed by some respondents who stated that image is very important to many users. The majority of users gravitate to software products that are functional, user-friendly with an excellent user interface, and not necessarily the best system because in most cases users do not understand the technical shortfalls that might exist in a software product. The verification and validation procedures which are 
conducted to ensure quality can be easily misunderstood by users of the system. It was suggested that the user community needs to participate in the design and development of the system more closely in an effort to reduce misunderstanding and lessen the likelihood of software defects.

Question \#5 looked at the fact that the variance explained by perception and IS quality on IS success was 0.781 or $78 \%$.

An $\mathrm{R}^{2}$ of 0.781 means that perception and information systems quality explains $78 \%$ of the variance in information systems success. The other factors that could be considered in this study would explain $22 \%$ of the variance. To this end, the respondents suggested the following factors as antecedents to IS success:

- Top management support

- Technical support

- Management of customer expectations

Both technical support and the management of customer expectations could be viewed as moderating variables for IS success. As a result, these two variables could be incorporated between IS quality and IS success in the revised research model. In addition to the factors above, the respondents made reference to developers' level of education, training, and experience as additional indicator variables for the 'People' construct. These factors are relevant because it is stated that software quality assurance and software process improvement courses are taught in many Canadian universities (Laporte and O'Connor 2016). However, it is proposed that these indicator variables be considered in future studies with a larger sample size.

Question \#6 sought answers to the question regarding why the loading on 'Organization Process Focus' was below the 0.700 threshold.

The definition of organization process focus (OPF) is plans to deploy process improvements based on a thorough understanding of the strengths and weaknesses of the organization's software development processes (SEI 2010). Based on this definition, most respondents believed that some firms might exercise priority shift from established developmental practices and routines to trying to get the software product as quickly as possible to the market because it is felt that less focus on established routines can speed up the delivery process. In other words, firms will sacrifice process maturity practices in an effort to improve their responsiveness to time-to-market. Time-to-market is a critical performance measure in the software industry (Jeong and Yoon 2016). One respondent went as far as saying that "too much process kills innovation" In addition, it was felt that OPF is a high level organizational practice and not a project management level practice. Project management practices are believed to have a more direct impact on software quality.

In general, there is a reluctance by employees to adopt new practices whether at the project management or organizational levels. This is coupled with the fact that there is a lack of understanding by some top executives regarding what is required in implementing process improvement programs. Furthermore, many top executives are more focused on the bottom line rather than process improvement. 
The final question (question \#7) was open-ended and asked respondents to reflect and share any observations or insights which they garnered from the study.

The study supports the notion that software process improvement (SPI) program positively impacts IS quality and IS success. However, a reasonable balance is needed among people, process maturity, technology and user perception because all factors have a positive impact on IS quality and IS success. In an effort to be successful firms must create a culture of knowledge sharing. It is believed that this is attainable because most Canadian firms place a lot of emphasis on training and development. A final comment by one respondent is that (1) age of the firm, (2) maturity of the firm and (3) size of the firm could be used as control variables in an attempt to increase the richness of the findings.

Based on the views of Canadian developers the initial research model was extended and a revised IS quality and success model is being proposed to the IS community as shown in Figure 3. A fourth construct called 'Organization climate' is added to the proposed research model, with its indicator variables being industry dynamics, team dynamics and top management support. As a result, the key determinants of IS quality are being proposed to be people, process maturity, technology and organization climate. In addition, technology support and expectation management are being proposed as moderating variables between IS quality and IS success. It is hoped that this proposed research model will be validated in future studies.

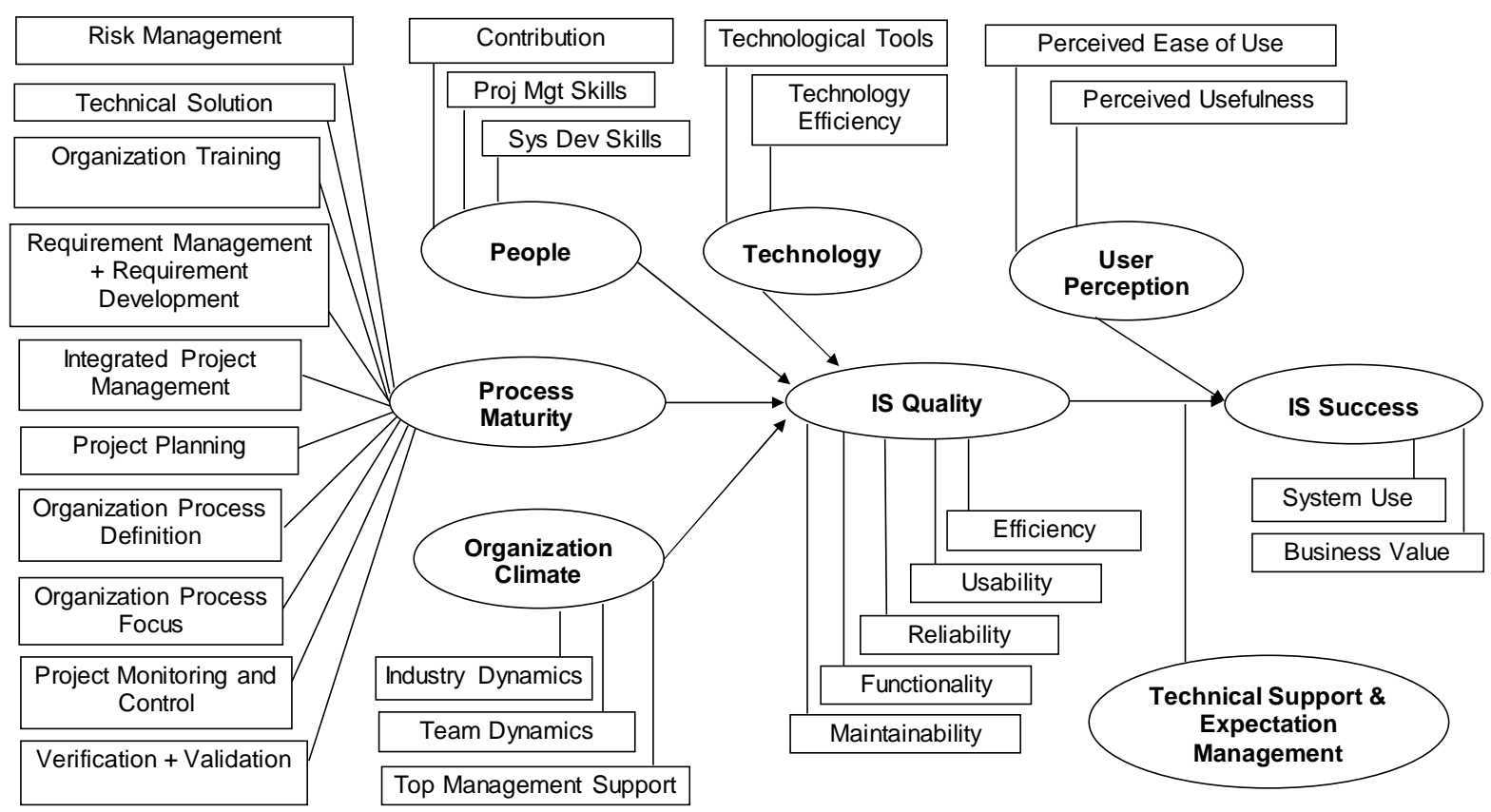

Figure 3. The Revised Research Model. 


\section{CONCLUSION}

The study confirmed the notion that people, process maturity and technology are key determinants of IS quality and also that user perception and IS quality are key determinants of IS success. More specifically, the survey discovered that developer skills and contribution had the greatest impact on information systems quality, over process maturity and the application of the latest technology. It is believed that the ability of developers and users to clearly articulate what is required and what should be delivered is critical in developing high quality software. Technology is believed to be a secondary tool which can be acquired by most Canadian software development firms. Hence, it is the human interpretation and application that matters in software development. This human resource is even more important in light of the fact that some of the knowledge that developers possess is tacit and as a result difficult to codify and express explicitly. In response to this challenge, some firms recruit knowledgeable developers from their competitors. This strategy is described as normative isomorphism in the institutional theory and if applied correctly, can allow firms to strive instead of merely survive.

The survey also discovered that user perception had a greater impact on IS success in comparison to IS quality. This discovery is consistent with the literature as it is posited that many technically sound and high-quality software products are not being used (Newman and Robey, 1992). Adoption and utilization of software products are dependent on the perception of users of its usefulness, ease of use and value-adding capability (Duggan 2006). It can be argued that software usage is a key measure to assess information systems success.

On the other hand, the interviews conducted by the researchers revealed that organization climate such as top management support, the social interactions and dynamics among project team members and the structural analysis of the industry are other factors which can influence the quality and success of the delivered software product. These insights if applied during the development and delivery of information systems can enhance the likelihood of producing high quality and successful software products and increase the competitiveness of these firms.

In addition, based on the views of Canadian developers, the research model was extended and a revised IS quality and success model is being proposed to the IS community. It is hoped that future studies will validate the proposed model. It is suggested that age of firm, the maturity of firm and firm size be used as control variables in future research to increase the richness of the findings.

\section{REFERENCES}

Bulatovic, J. (2011). Key issues in Information Systems Managment: A Serbia's Perspective (Delphi Study. Global Journal of Computer Science and Technology, 11(19 ), 34-50.

Chin, W. W. (2010). How to write-up and report PLS Analysis. In V. Esposito Vinzi, W. Chin, J. Henseler, \& H. Wang (Eds.), Handbook of Partial Least Squares: Concepts and Applications (pp. 655 - 690). Berlin Heidelberg: Springer-Verlag. 
Dalton, J. (2016). A guide to Scrum and CMMI: Improving agile performance with CMMI. CMMI, 1-130.

DiMaggio, P., \& Powell, W. W. (1983). The iron cage revisited: Institutional isomorphism and collective rationality in organizational fields. American Sociological Review, 482(2), 147- 60.

Dooley, K., Subra, A., \& Anderson, J. (2001). Maturity and its Impact on new product development project performance. Research in Engineering Design, 13 (1), 23 - 29.

Duggan, E. (2006). Tranquilizing the Werewolf that Attacks Information Systems Quality. IDEA Group Inc , 253-281.

Espinosa-Curiel, I., Rodríguez-Jacobo, J., \& Fernández-Zepeda, J. (2013 ). A framework for evaluation and control of the factors that influence the software process improvement in small organizations. Journal of software: Evolution and Process, 25(4), 393-406.

Fornell, C., \& Larcker, D. F. (1981). Evaluating Structural Equation Models with Unobservable Variables and Measurement Error. Journal of Marketing Research, 18(1), 39-50.

Gorla, N., \& Lin, S.-C. (2010). Determinants of software quality: A survey of information systems project managers. Information and Software Technology, 52, 602 - 610.

Hastie, S., \& Wojewoda, S. (2015). Standish Group 2015 Chaos Report - Q\&A with Jennifer Lynch. InfoQ, 1-24.

Humphrey, W. S. (1989). Managing the Software Process. Reading, MA: Addison-Wesley Professional.

Iversen, J., \& Ngwenyama, O. (2006). Problems in measuring effectiveness in software process improvement: A longitudinal study of organizational change at Danske Data. International Journal of Information Management, 26, 30-43.

Jeong, B. K., \& Yoon, T. E. (2016). Improving IT process management through value stream mapping approach: A case study. Information Systems and Technology Management, 13 (3 ), 389-404.

Kamel, S., Rateb, D., \& El-Tawil, M. (2009). The impact of ICT investments on economic development in Egypt. The Electronic Journal of Information Systems in Developing Countries, $36(1), 1-21$.

Krasner, H. (2001). Accumulating the Body of Evidence for The Payoff of Software Process Improvement. Software Process Improvement, 519-539.

Krishnan, M.S., \& Keller, M.I. (1999). Measuring process consistency: Implications for reducing software defects. IEEE Transactions on Software Engineering, 25(6), 769-781.

Laporte, C. Y., \& O'Connor, R. (2016). Systems and software engineering standards for very small entities: Accomplishments and overview. IEEE Computer Society, 84-87. 
Luftman, J., \& Ben-Zvi, T. (2010). Key Issues for IT Executives 2010: Judicious IT Investments Continue Post-Recession. MIS Quarterly Executive, 9(4), 1-16.

Merlo, E., Carneiro, T.C., \& Araujo, C.A. (2016). Factors influencing software migration decision: Case studies of ArcelorMittal Tubarao and the City Government of Serra, Espirito Santo. Journal of Information Systems and Technology Management, 13(3), 515-532.

Mignone, J., \& Henley, H. (2009). Impact of information and communication technology on social capital in aboriginal communities in Canada. Journal of Information, Information Technology, and Organizations, 4, 127-145.

Newman, M. \& Robey, D. (1992). A social process model of user-analyst relationships. MIS Quarterly, 16(2), 249-266.

Ngwenyama, O., \& Norbjerg, J. (2010). Software process improvement with weak management support: An analysis of the dynamics of intra-organizational alliances in IS change initiatives. European Journal of Information Systems, 19, 303-319.

Niazi, M. (2012). An exploratory study of software process improvement implementation risks. Journal of Software: Evolution and Process, 24, 877-894.

Niazi, M., \& Babar, M. (2009). Identifying high perceived value practices of CMMI level 2: An empirical study. Information and Software Technology, 51(8), 1231-1243.

Niazi, M., Babar, M., \& Verner, J. M. (2010). Software Process Improvement barriers: A crosscultural comparison. Information and Software Technology, 52, 1204-1216.

Paulk, M. C., Curtis, B., Chrissis, M. B., \& Weber, C. V. (1995). The Capability Maturity Model: Guidelines for Improving the Software Process. Reading, Massachusetts: Addison Wesley Longman, Inc.

Pino, F. J., Pardo, C., García, F., \& Piattini, M. (2010). Assessment methodology for software process improvement in small organizations. Information and Software Technology, 1044-1061.

Qureshi, S. (2009). Social and economic perspectives on the role of information and communication technology for development. Information Technology forDevelopment, 15(1), 13.

SEI. (2010). CMMI for Development, Version 1.3. Carnegie Mellon University: Software Engineering Institute CMU/SEI-2010-TR-033.

Standish Group (2013). Chaos manifesto 2013: Think big, act small. The Chaos Manifesto, 1-48.

Staples, M., Niazi, M., Jeffery, R., Abrahams, A., Byatt, P., \& Murphy, R. (2007). An exploratory study of why organizations do not adopt CMMI. Journal of Systems and Software, 883-895. 
Sulayman, M., Urquhart, C., Mendes, E., \& Seidel, S. (2012). Software process improvement success factors for small and medium Web companies: A qualitative study. Information and Software Technology, 54(5), 479-500.

Westlund, S. G., \& Hannon, J. C. (2008). Retaining talent: Assessing job satisfaction facets most significantly related to software developer turnover intentions. Journal of Information Technology Management, 19(4), 1-15. 


\section{APPENDIX A - Interview Questions on IS Quality and Success}

Dear Respondent,

I would appreciate your assistance in responding to the questions below regarding the findings of our 2013 survey on information systems quality and success in Canadian software development firms. The study found that:

- People skills and people contribution had the greatest impact on IS quality

- User perception and IS quality impacted IS success.

Attached overleaf are more detailed findings, as well as the definition of key terms.

1. Why do you think that people skills and contribution had the greatest impact on information systems (IS) quality over technology and process maturity in Canada?

2. Why do you think that technology had the lowest impact on information systems (IS) quality in Canada?

3. The variance explained by people, process maturity and technology on information systems (IS) quality [R2] is 0.760; What other factors could impact IS quality in Canada?

4. Why do you think that perception had a greater impact on information systems (IS) success over information systems (IS) quality in Canada? 
5. The variance explained by perception and IS quality on IS success is 0.781 ; What other factors could impact IS success in Canada?

6. Why do you think the loading on 'Organization process focus' was below the 0.700 threshold?

7. What other observations or insights have you made regarding this study?

Thank you for taking the time to respond to these interview questions Survey findings are overleaf 


\section{DEFINITION OF TERMS}

\section{Information systems (IS) quality:}

System that reliably produces required features that are relatively easy to access and use (Duggan, 2003). These features include functionality, maintainability, reliability, usability and efficiency.

DEFINITION OF PROCESS MATURITY PRACTICES (Source: Zubrow et al., 1994)

\section{Practices}

Risk Management (RSKM) is about identifying potential problems before they occur so that risk management activities can be planned and put into action as needed

Technical Solution (TS) is about designing, developing and implementing solutions to user requirements

Organization Training (OT) is about developing the skills and knowledge of project personnel so they can perform their roles effectively and efficiently

Requirements Management + Requirements Development (RM+RD) are about analysing and producing the system requirements and managing customer requirements

Integrated Project Management (IPM) is about managing the project in a manner that brings team members together in a coordinated manner

Project Planning (PP) establishes and maintains the plans that define project activities

Organization Process Definition (OPD) is to develop and maintain a usable set of software process assets that improve process performance across projects

Organization Process Focus (OPF) plans, implements and deploys process improvements based on a thorough understanding of the strengths and weaknesses of the organization's software development processes

Project Monitoring and Control (PMC) provides an understanding of the project's progress so that appropriate corrective actions can be taken when the project's performance deviates significantly from the plan

Verification + Validation (VV) describes the steps taken to ensure that the activities are performed in compliance with processes such as reviews, audits and software quality assurance, as well as checking that the software process produces the intended results such as formal walkthroughs and inspections 